\title{
Design and Evaluation to Internal Control of Shaanxi Textile Enterprises
}

\author{
Junxun Li \\ School of Management, Xi'an Polytechnic University \\ Xi'an 710048 , China \\ Tel: 86-29-8233-0197Ｅ-mail: dmezy@163.com \\ Xiaoyan Wei \\ Shaanxi Branch, Zhongrui Yuehua Certified Public Accountants Co., Ltd \\ Xi'an 710068, China
}

Tel: 86-29-8100-5139Ｅ-mail: yan5252020@sina.com

\begin{abstract}
Internal control means that enterprises in order to improve their self quality of business information, promote operation efficiency, fully obtaining and using the each kind of resources, under the related laws and regulations, so as to reach the fixed management goal, take the various kinds of restrictions and regulative organization, planning, methods and procedure in the enterprises internal. Design and evaluation internal control standards of textile enterprises, it is not only the urgent demand of enterprises development strategy; but also is an important measures to enterprises implementing scientific development view. This paper analyses present state of the internal control of Shaanxi textile enterprises, mainly expounds the design idea and evaluation process, methods of internal control from five factors.
\end{abstract}

Keywords: Shaanxi textile enterprises, Internal control, Design, Evaluation

In June 28th, 2008, the basic norm of the enterprises internal control was first issued by Ministry of Finance and other five ministries, the objective is to reasonable guarantee legal norms in business management, capital safety, truthfulness and integrality of financial report and relevant information, raise business efficiency and result and promoting enterprises realize the development strategy. It is well known that internal control as the internal mechanism of as self-accommodation and self-restriction mechanism of enterprises manufacturing and prosecution was plays an important role in enterprises management system. The establishment and implementation of internal control is not only the most basic part of enterprises, but also the safeguard of the survival and development. Otherwise, internal control is also an important part of risk management, the establishment of risk management target provides a prerequisite for the design and implementation of internal control, internal control is based on a risk assessment, and the implementation of the results should be evaluated. Shaanxi textile enterprises need sustained and healthy development, we must establish and implement effective internal control system, improve the governance structure, enhance the risk management, regulate the function of influence, strengthening supervision and restraint, encourage enterprises to achieve strategic objectives, and regulate development. With the implementation of strategic target of "construct the outstanding western province", as a pillar industry of Shaanxi province in the textile industry, it is high time to establish and implement effective internal control target.

\section{The present situation of Internal Control of Shaanxi Textile Enterprises}

The most Shaanxi textile enterprises was founded in the 50's -60's of last century, for a long time, owing to the influence of "three multi and one heaviness" (employment textile workers multi, difficulties enterprises multi, questions left over multi, high society burden), together with the factors that the weakness of enterprises internal control and financial regurgitation feeding are less, these enterprises has confronted difficulties. Into the 90 's of 20 Century, this industry occurred situation of continuity operation loss, through "the reduction of products and depletion of numbers, merger and reorganization" and other measures, in 2000, provincial textile industry albeit achieves turning losses into profits, but the economic gap has been widened between Shaanxi textile enterprises and coastal provinces. To reject the equipment and fund factors, one of a very important reason is internal control system are not perfect enough, because of the textile industry belongs to meager profit operation, once the managers had insufficient understanding to the internal control, it will inevitably become formalization, the enterprises internal friction will be large, and the pressure of cost also increased. According to investigation, current many enterprises still adopt the primitive and backward production processes and extensive management methods, so as to cause poor quality of yarns and grey fabric, materials consumption is high, enterprises low profitability, income generally lower of employee, the lack of attraction and cohesion, its lead to many brain drain, sustainable development is subjected severe obstruction due to internal control absence. Taking the Tanghua groups Shaanxi company for example, the enterprise has a long history state-owned with 
more than 36820 staffs, its 5 enterprises of subsidiary has policed bankruptcy row-column by state council in this year, and decided allocate to the local government management. Meanwhile, some state-owned textile enterprises and nongovernmental enterprises distribute in the zone of central shaanxi plain, they are lack strict internal control system, its internal control system mainly exist locomotors activity of each manager,so it has high casualness, meanwhile, it's usually incoherence in implementation process. Most textile enterprises are invalidation of internal control; it has become the "necklace" of the sustainable development of the Shaanxi textile enterprises. In 2008, due to all kinds of costs continuous rising, it is restricted to improving product price, the profit margins are continually compressed of textiles, some enterprises has fall into predicament of no order can be making, many enterprises also has fall into predicament of the order sufficient but no profit, or the order increasing but its profits decrease.

\section{The design of Internal Control of Shaanxi Textile Enterprises}

In view of the present situation of Shaanxi textile enterprises, when we are designed the internal control system, we are should from five aspects fully considered such as internal environment, risk assessment, control activity, information and communication, internal supervision.

\subsection{Design of the internal environment}

Internal environment is the basis for the implementation of internal control, it's generally includes following 5 factors: the governance structure, the organization establishment, the distribution of powers and responsibilities, the internal audit, the human resource policy and the enterprises culture etc.

(1) The design of the governance structure, the organization establishment and the distribution of powers \& responsibilities: According to the "company law" and "articles of association" regulations, Shaanxi textile enterprises should to set up sound corporate administrative structure. In order to ensuring the company's internal control system to be implemented, so the company management according to the organizational structure step by step authorization. The workers congress or the general meeting of shareholders is the top authorities to implement management and supervision of the company's internal control. The board of directors as a decision-making of permanent establishment, responsible for the workers congress or the general meeting, to the company's operating activities important decision problems in the decision-making deliberation and make a decision, or submitted deliberation to the workers congress or the general meeting. The board of supervisors is a supervision institution of company; it's responsible for monitor to the company director, the manager tier and corporate finance.

(2) The design of the internal audit system: The internal audit except auditing account books of enterprises, it is also including customs officer, evaluated internal controlling system is perfect or not and inner organizations execution efficiency, then put forward some suggestions and report of the enterprise highest management department. Design should be considered from three aspects: First, independent organizations. It can be independent exercise the audit supervision and have a certain authority, also it have a certain power of appointment to the problems or situation of the audit process. Second, staff is refinement and efficient, but also meet the requirements of internal audit work. Third, it should be coordinated to the other functions of institutions, coordinate with each other, restriction and promote.

(3) The design of the human resource policy: The human resource policy is an important scarce resource; it is one kind of tools of the enterprises to gain competition advantage. Its design should including the human resource management organization security of functions, the human resource planning, and the personnel selection and added the human resource education and training, the staff's assessment and evaluation, the salary and incentive mechanism, also including the mechanism to leave talents etc.

(4) The design of the enterprises culture: The enterprises culture is designed in order to realize its mission, unification thought of the textile workers, concepts, attitude, behaviors and values. So it is urgent to achieve the following points: (1)scouring and introduced into the elements of enterprises culture, constructing the cultural system of textile enterprises, formation a spirit of enterprise strength, developing cultural competitiveness;(2) The establishment of enterprise culture working groups, design the organization of the enterprises culture; (3)Penetration the cultural idea of those that can have a lasting invigorative function. The enterprises culture should outstanding culture of innovation, Develop staff handbook and around its spirit level, substance level and system level construction.

\subsection{Design of the risk assessment}

For a long time, the risk management more emphasis the risk process control and ex-post control of the textile enterprises, due to the lack of risk-warning mechanism, so lead to the risk monitoring index is inadequate, the basic construction comparatively weakness of the monitoring system. When we design the internal control, must base on the "basic norms of corporate internal controls" as a criterion, considering the internal control and efficiency from the point of the strategic risk.

The internal control turning the strategic risk to implement control, it's not a concept, but it is need a transformation from the guiding thought and conduct standard of the corporate governance and management layer, also needed the 
guarantee of corporate governance mechanism, needed tangible strategic target and can combination human, money and material resources of all support to realization strategic targets, although these condition and foundation showed different in different enterprises, it's impossible to set a unified model, but also its attention point of risk almost same. In the design to be followed rules of comprehensiveness, of early warning, of maneuverability and dynamic character, through investigation to the existing textile enterprises internal control implement situation, making a relevant test, then evaluated to its soundness, rationality and effectiveness, in order to determine whether dependence the properties, scope, emphasis and methods of the internal control and substantive tests. The specific contents included: the risk assessment process, target system, internal risk and external risks, the risk identification, the risk determined importance and coping strategy etc.

\subsection{Design of the control activity}

The control activity means enterprises based on risk assessment results, by using the corresponding control measures, making the risk at can be endure scope. The specific contents included: separation of interlinked duties, major risk authorization control, audit and approval control, budget control, safety of assets, reporting system, financial report authenticity, and analysis control of the economic activities, performance appraisal control and information system control etc.

\subsection{Design of the information and communication}

The so called information and communication mean the enterprises timely and accurate collecting, transfer with internal controls-related information, ensure the information effective communication between enterprise internal and enterprise external. In the design to be should cover the information management system of textile enterprises, enterprises internal information control, enterprises external information control and enterprises communication mechanism etc.

\subsection{Design of the internal supervision}

The internal supervision means that enterprises supervise and inspect to the internal control establishing and the situation of implementation, evaluate effectiveness of internal controls, find deficiencies of internal control, and enterprise should promptly be improved. Including:

(1) Design of monitoring institution: Because of the Shaanxi state-owned textile still dominate, in order to ensure the security and integrity of the state-owned assets, the enterprises should set up ministry of audit, equipped with full-time internal audit staff, exercise of independent audit function, make some internal audit and supervision on financial income and expenditure of enterprises and economic activities.

(2) Supervision system design: In order to improve the corporate governance structure, standardize the company economic behavior, and safeguarding legitimate rights and interests of the shareholders, Shaanxi textile enterprises should establish a system of internal audit, to review and evaluate the economic activities of enterprises authenticity, legitimacy and the effectiveness of internal controls. All major issues should be established into a sound and reasonable system of internal control system.

(3) Internal control deficiencies reporting and improved: we recommend establish internal audit departments; regularly check the deficiencies of company's internal control system, to assess their effectiveness and efficiency of the implementation and timely suggestions for improvement. Internal audit staff should check the internal control deficiencies and unusual items, and write recommendations for improvements into the internal audit report truthfully.

(4) Internal control self-assessment: Use of specific methods by regular to test the implementation of internal control and write assessment reports, as the main decision for the Enterprise management.

In a word, the design of Internal control should be operate around the control environment, it is not only the basic of the other four related factors, but also the framework of enterprise discipline and internal control, it directly impact on cognitive about the internal control of the business staff, If there is no effective control environment, perhaps there will not have the four other outstanding elements which is have outstanding results.

\section{The evaluation of Internal Control of Shaanxi Textile Enterprises}

The traditional internal control evaluation methods mainly rely on the subjective judgment of professionals from the qualitative aspects of the evaluation, so in this way will lack some scientific nature. Based on the requirement of Basic regulation of enterprise internal control, combine with the Shaanxi textile enterprise's own characteristics, the evaluation of internal controls should focus on two aspects: firstly, construct the textile enterprises in Shaanxi internal control evaluation index system. Including research and analysis of the enterprise internal control system design a system of indicators for evaluation consist of the title of every indicators, content, standards, weight, etc. Secondly, make use of the complete design evaluation index system, through the collection of qualitative and quantitative evaluation information, compare the evaluation scores and evaluation index and standard, and then reflect the merits of internal control in Shaanxi textile enterprises, draw integration evaluation conclusions. This paper will pay more attention on discussing evaluating the internal control textile enterprises in Shaanxi by the Matrix Method. 


\section{1 major evaluation steps}

(1)The enterprise internal control will be divided into a number of elements (control environment, risk assessment, information systems and communication, internal supervise), they were given different weights (Table 1), each element contains a number of key indicators or key factors, there are six key indicators, the control environment should include elements of integrity and moral values (weight 0.25 ), competence ability (weight 0.15 ), the level of participation of governance (weight 0.15 ), management concept and style (weight 0.15 ), organizational structure and responsibility division (weight 0.15 ), human resources policies and practices (weight 0.15 ), which confirm the scoring of each factor under different elements.

(2) Confirm the importance of all key indicators or factors to the various elements, and figure out the integrated scoring of every element.

(3) Establish the important coefficient of various elements to the internal control, and figure out the integrated scoring coefficient of internal control.

(4) Establish the scoring standards of internal controls under different conditions, and figure out overall score of internal control (Table 2).

\subsection{Internal control evaluation of the overall score calculation}

(1) Calculate the elements of control environment indicators score

(1)Firstly, let the evaluated textile enterprises in Shaanxi to be the target, calculate the score of key factor which is the subordinate of the integrity and moral values under different conditions (Include the regulation of conduct, corporate culture, management of the exemplary role, etc.);

Secondly, calculate the integrated score coefficient by the matrix method of the integrity and moral values;

Matrix composite coefficient $=$ Evaluation factors coefficient matrix $\times$ Scoring matrix

(2) Use of the similarly methods calculated the Matrix composite coefficient competence ability, the level of participation of governance, management concept and style, organizational structure and responsibility division, human resources policies and practices;

(3) Calculate the control environment scoring matrix;

Control environment scoring matrix $=$ Evaluation factors coefficient matrix $\times$ the subordinate key indicators of the various elements of comprehensive scoring matrix

(4) Normalize the general indicators coefficient matrix;

(5)Determine the control environment under the four condition "excellent, good, medium and poor" scoring matrix;

(6) Calculate the general score of the control environmental factors indicators; the general score of the control environmental factors indicators $=$ the general indicators of coefficient matrix $\times$ the scoring matrix of the elements in different conditions.

(2)The index scores of other elements of internal control (risk assessment, information systems and communication, internal supervise) is similar to the former principle.

(3)According to the weight of internal control elements in the internal control factors (Table 1), figure out the integrated assessment score of internal control.

\section{Conclusion}

In the 2008China Cotton Industry Development Summit Forum and the International Cotton Trade Fair, the experts made it clear that the textile industry in eastern developed regions should be promote to transform to resources, land, and labor advantage in the western region gradually, and seek more cost competitive advantage. In October 2007, Xi'an government formulated the "textile city in Xi'an of the revitalization development planning framework". This purpose is to correctly guide textile enterprises in Shaanxi by the government to promote the healthy development. July 16th, 2008, the largest corporate bankruptcy so far in Shaanxi province-Tanghua designated enterprises under the central policy of the insolvency of the group officially launched. This bankruptcy is not an end, but to promote the textile enterprises in Shaanxi have a greater development in the future. These days, our country enhances some textiles, clothing and other goods of export tax rebate rate from 11 percent to 13 percent. All these indicate that favorable external environment will help the textile industry in Shaanxi to construct the system of internal control. In the near future, through a series of internal control construction, the textile in Shaanxi will reproduce the past glory.

\section{References}

Ministry of Finance People's Republic of China, etc. (2008). About print and published the "basic regulation of internal control". Beijing: Accounting .No.7. 
Zhao, Boping. (2008). Tanghua Groups policy initiated bankruptcy. Xi'an: Huashang Newspaper. July 17 , p: A7.

Luo, Qing. (2007). Internal control design, test and evaluation. Beijing: Economic Science Press. p357-369.

Yan, Jiamin. (2007). Shaanxi Textile Industry Development and Reform senior seminar held in Xi'an. Beijing: China Textile Newspaper. May 29, p: 1.

Table 1. Internal control factor weight

\begin{tabular}{|c|c|c|c|c|c|}
\hline Element & $\begin{array}{c}\text { Control } \\
\text { environment }\end{array}$ & $\begin{array}{c}\text { Risk } \\
\text { assessment }\end{array}$ & $\begin{array}{c}\text { Information } \\
\text { and } \\
\text { communication }\end{array}$ & $\begin{array}{c}\text { Control } \\
\text { activities }\end{array}$ & $\begin{array}{c}\text { Internal } \\
\text { supervise }\end{array}$ \\
\hline Weight & 0.25 & 0.15 & 0.2 & 0.25 & 0.15 \\
\hline
\end{tabular}

Table 2. Internal control evaluation index score standards

\begin{tabular}{|c|c|c|c|c|}
\hline \multirow{2}{*}{ Item } & \multicolumn{3}{|c|}{ Meet the key factors } & \multirow{2}{*}{$\begin{array}{c}\text { Do not meet the key } \\
\text { factors }\end{array}$} \\
\cline { 2 - 4 } & excellent & good & medium & 0 \\
\hline Score & 1 & 0.8 & 0.6 & 0 \\
\hline
\end{tabular}

